\title{
Antimicrobial Performance of Thermoplastic Elastomers Containing Zinc Pyrithione and Silver Nanoparticles
}

\author{
Michele Pittol $^{a}$, Daiane Tomacheski ${ }^{a, b}$, Douglas Naue Simões ${ }^{a, b}$, Vanda Ferreira Ribeiro ${ }^{a, b}$, Ruth \\ Marlene Campomanes Santana
}

\author{
${ }^{a}$ Softer Brasil Compostos Termoplásticos, Campo Bom, RS, Brazil \\ ${ }^{b}$ Department of Materials Engineering, Laboratory of Polymers - LAPOL, Universidade Federal do Rio \\ Grande do Sul, Porto Alegre, RS, Brazil
}

Received: January 18, 2017; Revised: May 11, 2017; Accepted: June 20, 2017

\begin{abstract}
The purpose of the present study was to evaluate the antimicrobial potential of styrene-ethylene/ butylene-styrene based thermoplastic elastomers (TPE) incorporated with zinc pyrithione ( $\mathrm{ZnPT}$ ) and silver nanoparticles (AgNano). Japan Industrial Standard was applied to evaluate the antimicrobial potential of incorporated TPE compounds against Staphylococcus aureus (S. aureus) and Escherichia coli (E. coli). Antifungal action was evaluated against Aspergillus niger, Candida albicans and Cladosporium cladosporioides. Samples prepared with ZnPT eliminated $99.9 \%$ of the E. coli and 99.7 $\%$ of the $S$. aureus population, and presented an inhibition zone in the fungal assay. Samples prepared with AgNano eliminated $99.7 \%$ of the E. coli and $95.5 \%$ of the $S$. aureus population. There was no inhibition zone in samples containing AgNano; however, these samples did not present fungal growth on their surfaces. TPE samples containing ZnPT showed biocidal activity against the microorganisms tested and can be used to develop antimicrobial products.
\end{abstract}

Keywords: Antimicrobial polymer, silver nanoparticles, thermoplastic elastomers, zinc pyrithione

\section{Introduction}

Styrene-ethylene/butylene-styrene (SEBS) based thermoplastic elastomers (TPE) are employed in a wide range of products with elastic properties, such as remote control keyboards, cell phone covers, tooth brush cables, toys and others. The World Health Organization has disclosed that the most common route for the transmission of diseases is by contact with surfaces contaminated with infectious droplets from coughs, sneezes or speech produced by contaminated persons; that can remain on surfaces for days ${ }^{1}$, and hands of health-care workers ${ }^{2}$.

With that in mind, assuming that a biofilm can build up within a few hours ${ }^{3}$ and considering that these devices are not usually cleaned properly, the SEBS-based TPE materials can become a place for microbial growth, leading to material degradation and ultimately the spread of infections. In this sense, the production of SEBS-based TPE materials with antimicrobial properties is important in order to maintain microbial cells at low counts ${ }^{4}$.

An effective biocide should be able to migrate to the polymer surface, where it can act inhibiting susceptible surface-colonizing cells, and hence delay biofilm accumulation ${ }^{5}$. Antimicrobial additives can be categorized as organic and inorganic. Among organic additives, 5-chloro-2-(2,4dichlorophenoxy) phenol (Triclosan ${ }^{\circledR}$ ), isothiazolone and zinc pyrithione (ZnPT) have shown efficacy and fast results toward a large range of microorganisms, such as Candida albicans, Escherichia coli, Pseudomonas aeruginosa,

\footnotetext{
* e-mail: mipittoll@gmail.com
}

Salmonella choleraesuis and Staphylococcus aureus ${ }^{6}$. The industrial use of $\mathrm{ZnPT}$ is more common as anti-dandruff in shampoo and soap, and in body wash due to its low water solubility, lack of color and odor when applied in cosmetics ${ }^{7-9}$. As antifungal and antibacterial, this substance has been used in paints ${ }^{10}$, textiles ${ }^{11}$ and polymeric matrices as polyurethane foam $^{6}$ and polyvinyl chloride (PVC) ${ }^{12}$. The biocide action of $\mathrm{ZnPT}$ relies on the inhibition of membrane transport and efflux pumps of microorganisms taunting the accumulation of toxic substances inside the cells ${ }^{13,14}$.

The inorganic additive used in the present study was a nanoform of silver (AgNano). One of the mechanisms of silver ion release from polymeric matrix occurs through contact of metallic silver with dissolved oxygen in moisture ${ }^{15,16}$. Once released, AgNano will act on the microbial cells through several modes of action ${ }^{17}$, such as: (a) nanoparticles can bind to proteins of vital enzymes presents in the mycelial ${ }^{18}$ and bacterial ${ }^{19}$ cell wall, (b) also can damage the cellular structures and biomolecules ${ }^{20}$, (c) cause toxicity by the generation of reactive oxygen species ${ }^{21}$, besides (d) affecting in the molecular and cellular routes of bacteria. Recently, silver nanoparticles have been pointed out as the most innovative and efficient antibacterial form ${ }^{16}$, since they provide better dispersion in the polymeric matrix ${ }^{22}$. However, it is reported that in incorporated polymers, ZnPT leaches from the bulk toward to polymer surface in a faster way than silver. These differences in release rates could make silver additive less readily effective, but with bigger long-term effects than $\mathrm{ZnPT}^{23}$. 
Besides the antimicrobial efficacy, in order to be widely applied in consumer goods, antimicrobial TPEs needs to maintain their mechanical properties and color qualities. Toward to this end, this article evaluated the antimicrobial potential of TPE compounds incorporated with zinc pyrithione ( $\mathrm{ZnPT})$ and nanosilver (AgNano) in inhibiting the growth of microbial strains. This study describes: (i) the mechanical and color characteristics of metal-incorporated TPE compounds, (ii) the bactericidal performance of incorporated TPE compounds against Gram-positive and Gram-negative bacteria, (iii) the fungicide performance of incorporated TPE compounds against the yeast Candida albicans and filamentous fungi Aspergillus niger and Cladosporium cladosporioides.

\section{Material and Methods}

\subsection{Additives}

Two additives were tested, a zinc pyrithione in a plastic compound (polypropylene) in a formulation with high concentration of additives to improve handling (masterbatch) (FBP 435, ZnPT) and colloidal suspension of silver nanoparticles (AgNano 6011, AgNano), both supplied by Ipel (Itibanyl Special Products Ltd., São Paulo, Brazil). The additives were included at a proportion of $1.5 \%$ by weight (as recommended by the supplier) in a TPE formulation compounded by styrene-ethylene/butylene-styrene copolymer (SEBS, 32\% styrene, ethylene/butylene 32/68, linear, $\mathrm{M}_{\mathrm{w}}$ $214.8 \mathrm{~g} \mathrm{~mol}^{-1}, \mathrm{M}_{\mathrm{w}} / \mathrm{M}_{\mathrm{n}}=1.3$ ), polypropylene homopolymer (PP, melt flow index $1.5 \mathrm{~g} 10 \mathrm{~min}^{-1}$ at $230^{\circ} \mathrm{C}, 2.16 \mathrm{Kg}$ ), white mineral oil (64\% paraffinic and $36 \%$ naphtenic), at the ratio of 30/20/50, respectively. Antioxidant Pentaerythritol Tetrakis (3-(3,5-di-tert-butyl-4-hydroxyphenyl)propionate) (0.1\%) was added to avoid thermal degradation during processing.

\subsection{Preparation of the compounds}

The samples were prepared using a co-rotating double screw extruder (L/D 40 and $16 \mathrm{~mm}$ screw diameter (AX Plásticos)), with a temperature profile ranging from $170^{\circ} \mathrm{C}$ to $190^{\circ} \mathrm{C}$, speed of $300 \mathrm{rpm}$, feed rate of $1.5 \mathrm{~kg} \mathrm{~h}^{-1}$ and melt discharge temperature of $200^{\circ} \mathrm{C}$. The extrusion parameters were kept constant throughout the tests. Test samples in 2 $\mathrm{mm}$ thick plate form were prepared using injection molding machine (Haitian, PL860) at $190^{\circ} \mathrm{C}$ and an injection pressure of 17 bars. After molding, the test specimens were conditioned at $23 \pm 2^{\circ} \mathrm{C}$ and $50 \pm 5 \%$ relative humidity for $24 \mathrm{~h}$ before testing. A Standard sample with the same composition of the compounds without the inclusion of additives was also prepared.

\subsection{Characterization of the compounds}

\subsubsection{Mechanical properties}

The tensile at break, modulus at $100 \%$, and elongation at break properties of the compounds were analyzed according to ASTM D 412 method. Dumbbell samples types C were tested in universal testing machine EMIC DL 2000 with a $0.1 \mathrm{kN}$ load cell at room temperature. The cross-head speed and gauge length of the apparatus were $500 \mathrm{~mm} \mathrm{~min}^{-1}$ and $25 \mathrm{~mm}$, respectively. The determination of the hardness Shore A of the compounds were performed according to ASTM D 2240, using $6 \mathrm{~mm}$ square samples and a Durometer Bareiss HPE-A, with a reading time of 3 seconds. For all the measurements mentioned above the result was the mean \pm standard deviation of five test samples. The density measurement was performed in accordance to ASTM D 792, method A, namely hydrostatic method, with $2 \mathrm{~mm}$ square samples. For density the result was the mean \pm standard deviation of three test samples.

\subsubsection{Color analysis of treated samples}

Color fastness was determined by exposing the samples to an Osram Ultra-Vitalux 300W UV lamp for 96 hours, color fastness delta values $(\Delta \mathrm{E})$ were obtained using a portable colorimeter Delta Color Colorium 2 model. CIELAB color space was used to determine parameters $L^{*}, a^{*}$, and $b^{*}$. $L^{*}$ value ranges from 0 (black) to 100 (white); $\mathrm{a}^{*}$ value ranges from -80 (green) to 100 (red); and $b^{*}$ value ranges from -80 (blue) to 70 (yellow). $\Delta \mathrm{E}$ was calculated as a global parameter of color alteration according to equation 1 .

$$
\Delta E *=\sqrt{\left(\Delta L^{*}\right)^{2}+\left(\Delta a^{*}\right)^{2}+\left(\Delta b^{*}\right)^{2}}
$$

\subsubsection{Analysis of fourier transform infrared spectroscopy}

Fourier transformed infrared spectroscopy attenuated total reflection (FTIR-ATR) of surface samples was recorded on a PerkinElmer spectroscope (Frontier). Each spectrum was recorded with a total of 10 scans at a resolution of 4 $\mathrm{cm}^{-1}$ at room temperature. Spectrum software was used for spectra analysis.

\subsection{Antimicrobial studies}

\subsubsection{Microbial strains and culture conditions}

Two bacterial species, Escherichia coli ATCC 8739 (E. coli) and Staphylococcus aureus ATCC 6538 (S. aureus) 
and three fungal species Aspergillus niger ATCC 6275 ( $A$. niger), Candida albicans ATCC 10231 (C. albicans) and Cladosporium cladosporioides IMI 178517 (C. cladosporioides) were obtained from the Andre Tosello Fundation culture collection. The stock cultures were freeze-dried and stored at $20^{\circ} \mathrm{C}$. Before use, bacterial cultures were resuscitated and grown in Brain Heart Infusion Broth (Oxoid) and in Potato Dextrose Agar (Oxoid) for fungus overnight at $37^{\circ} \mathrm{C}$. Both media were prepared following the manufacturer's protocol. All media were sterilized by autoclaving at $121^{\circ} \mathrm{C}$ for $15 \mathrm{~min}$.

\subsubsection{Antibacterial test}

Japan Industrial Standard (JIS) Z 280124 was applied to evaluate antibacterial efficiency of samples against $S$. aureus and E. coli strains. Prior the assay, the TPE specimen (square $-50 \mathrm{~mm} \times 50 \mathrm{~mm}$ ) were disinfected with ethanol and then exposed to ultraviolet (UV) light with the wavelength between 300 and $400 \mathrm{~nm}$ for $2 \mathrm{~h}$. The distance between the UV light and the specimen was kept at $10 \mathrm{~cm}$. After that, the samples were placed in a sterile Petri dish followed by an inoculation of $7.6 \times 10^{6} \mathrm{CFU} \mathrm{cm}^{-2}$ of E. coli and $3.5 \times 10^{6} \mathrm{CFU}$ $\mathrm{cm}^{-2}$ of $S$. aureus suspension on the specimen surface, and covered with polyethylene film (as shown in Figure 1). All of them were incubated for $24 \mathrm{~h}$ at $35 \pm 1^{\circ} \mathrm{C}$. The reduction in bacterial population (percentage, $\%$ ), was calculated from the difference between the number of colony forming units (CFU) per square centimeter at zero hour (initial) and after 24 hours of incubation, equation (2):

$$
E f(\%)=\frac{P i-P f}{P i}
$$

Where $E f$ is the reduction in bacterial population (percentage, \%), Pi and Pf are, respectively, initial and final bacterial population (colony forming units per square

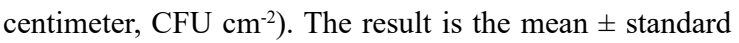
deviation of three test samples.

Antibacterial effectiveness - $R$, was validated in accordance with JIS Z 2801, with the equation (3):

$$
R=U t-A t
$$

Where $U t$ is the average of logarithm numbers of viable bacteria after inoculation on control (additive free) sample after $24 \mathrm{~h}$ and $A t$ is the average logarithm numbers of viable bacteria after inoculation in antibacterial samples after 24 h. To be considered effective, $R$ must be $\geq 2.0$.

\subsubsection{Fungal growth test}

The Brazilian Association of Technical Standards (ABNT) NBR $15275^{25}$ was used to evaluate the compounds' antifungal abilities toward the fungi $A$. niger, $C$. albicans and C. cladosporioides. Three test samples (square - $25 \mathrm{~mm}$ x $25 \mathrm{~mm}$ ) for each additive concentration were sterilized with ultraviolet (UV) light and then placed in a sterile Petri dish with agar and $100 \mu \mathrm{L}$ of $1 \times 10^{5}-1 \times 10^{6}$ spores $\mathrm{mL}^{-1}$ of fungus suspension were inoculated on the specimen surface. All of them were incubated for seven days at $30 \pm 2{ }^{\circ} \mathrm{C}$. The presence of an inhibition zone (after $48 \mathrm{~h}$ incubation) and hyphal growth (after seven days incubation) were evaluated with a stereoscopic microscope. The results were expressed in millimeters of diameter of inhibition zone and the percentage of the specimen area covered by the fungus.

\subsection{Statistical analysis}

Statistical analysis of variance (ANOVA) and t-test was applied in tensile strength at break, modulus at $100 \%$, elongation at break, hardness, density and antibacterial results using MYSTAT, student version 12 (Systat Software, Inc., CA, USA). The level of significance was set at 0.05.

\section{Results and Discussion}

In the materials industry, the control of standard characteristics such as mechanical properties is important to ensure the product quality. Therefore, the incorporation of an additive in polymeric materials should allow for an improvement in performance without prejudice to the original characteristics.

Table 1 shows the variations in mechanical properties after the incorporation of $1.5 \%(\mathrm{w} / \mathrm{w})$ of $\mathrm{ZnPT}$ and AgNano. There were no significant changes in tensile and elongation at break values of metal-incorporated samples when compared to the Standard compounds (tensile $-\mathrm{p}=0.47$; elongation at break $\mathrm{p}=0.09$ ). However, the modulus, density and hardness values in $\mathrm{ZnPT}$ incorporated compounds presented a significant difference $(\mathrm{p}<0.05)$ when compared with Standard and AgNano compounds, which could be due to the polypropylene fraction in masterbatch, present in $\mathrm{ZnPT}$ additive, that have higher modulus, density and hardness than the SEBS (Table 1).

In order to verify if the addition of $\mathrm{ZnPT}$ and AgNano may cause any color modification or molecular organization difference in TPE incorporated materials, a color fastness and a FTIR-ATR analysis were performed.

As seen in Table 2, with the incorporation of $\mathrm{ZnPT}$ a loss of transparency $\left(\mathrm{L}^{*}\right)$ was noted in TPE samples, which may be related to the high amount of polypropylene present in the masterbatch. After 96 hours of UV light, the sample incorporated with ZnPT turned completely yellow. This color modification is visually perceptible in Figure 2 and proven by improving the yellowness value $\left(b^{*}\right)$, that leapt from 1.9 to 22. This modification in color of ZnPT-loaded material can be related to its extreme instability ${ }^{12}$ accelerated by UV light resulting in photodegradation ${ }^{26}$. 

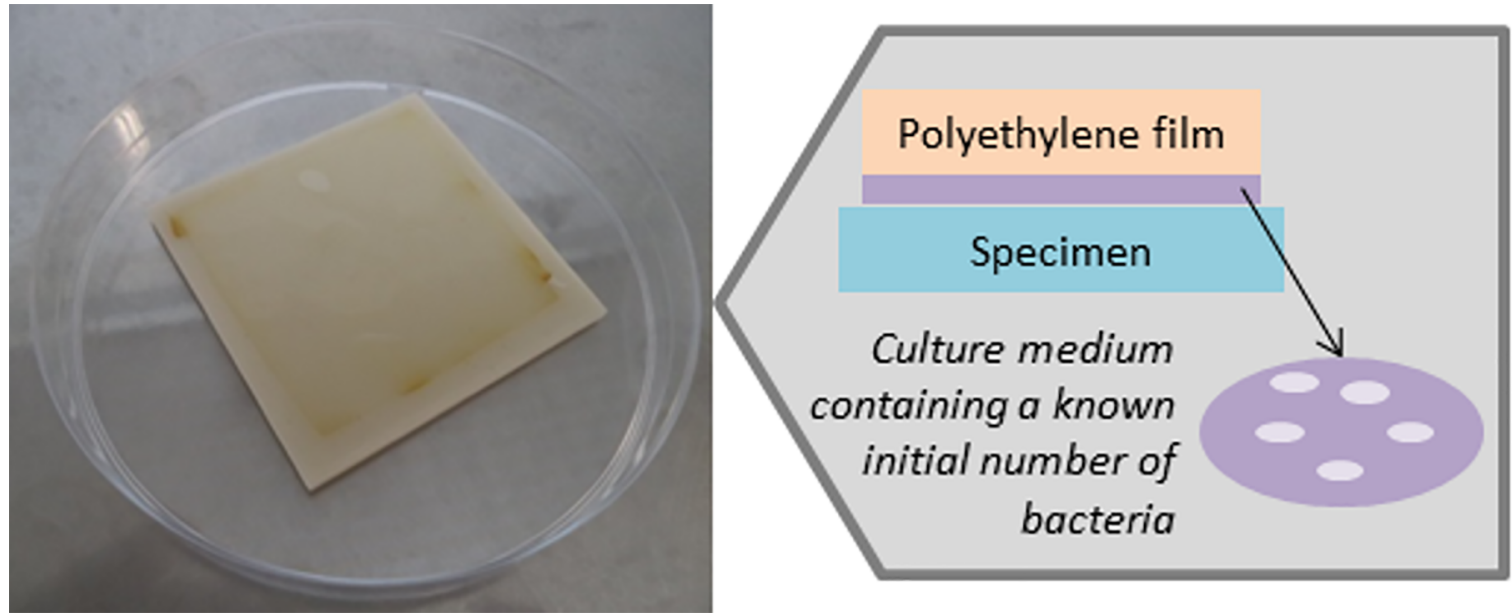

Figure 1. Representative scheme of antibacterial assay composed by TPE specimen, bacterial suspension, and the polyethylene film.

Table 1. Mechanical properties of Standard sample and sample incorporated with $1.5 \%$ of ZnPT and AgNano.

\begin{tabular}{lccccc}
\hline Compounds & Tensile strength at break, MPa & $\begin{array}{c}\text { Modulus at 100\%, } \\
\text { MPa }\end{array}$ & $\begin{array}{c}\text { Elongation at } \\
\text { break, } \%\end{array}$ & Density, g/cm ${ }^{3}$ & Hardness, Shore A \\
\hline Standard & $10.3 \pm 1.0$ & $2.5 \pm 0.0$ & $771 \pm 39$ & $0.889 \pm 0.001$ & $64 \pm 2$ \\
ZnPT & $10.6 \pm 0.5$ & $2.7 \pm 0.1^{\text {(a) }}$ & $747 \pm 25$ & $0.893 \pm 0.001^{(\text {a) }}$ & $70 \pm 2^{\text {(a) }}$ \\
AgNano & $10.9 \pm 0.5$ & $2.5 \pm 0.0$ & $793 \pm 23$ & $0.890 \pm 0.001$ & $65 \pm 2$ \\
\hline
\end{tabular}

(a) Statistically different from the Standard $(\mathrm{p}<0.05)$

Table 2. Color analysis of Standard samples and TPE incorporated with 1.5\% of $\mathrm{ZnPT}$ and $1.5 \%$ of AgNano before and after $96 \mathrm{~h}$ of UV light exposure.

\begin{tabular}{|c|c|c|c|c|}
\hline Samples & $\mathrm{L}^{*}$ & $a^{*}$ & $b^{*}$ & $\Delta \mathrm{E}$ \\
\hline Standard & 72.23 & 0.44 & 4.03 & - \\
\hline Standard (after 96 h) & 72.88 & 0.75 & 6.33 & $2.4^{(\mathrm{a})}$ \\
\hline $\mathrm{ZnPT}$ & 72.05 & -2.74 & 1.86 & $3.17^{(b)}$ \\
\hline ZnPT (after 96 h) & 69.66 & 1.66 & 22.04 & $20.8^{(\mathrm{c})}$ \\
\hline AgNano & 67.91 & 0.15 & 11.14 & $10.56^{(\mathrm{b})}$ \\
\hline AgNano (after 96 h) & 68.33 & 2.98 & 20.14 & $9.4^{(\mathrm{d})}$ \\
\hline
\end{tabular}

Note: L 0 (black) to 100 (white); $\Delta \mathrm{a}^{*}-80$ (green) to 100 (red); $\Delta \mathrm{b}^{*}-80$ (blue) to 70 (yellow); $\Delta \mathrm{E}$ global parameter of color alteration. (a) comparing with initial Standard; ${ }^{(b)}$ comparing with Standard; ${ }^{(c)}$ comparing with initial ZnPT; ${ }^{(d)}$ comparing with initial AgNano.
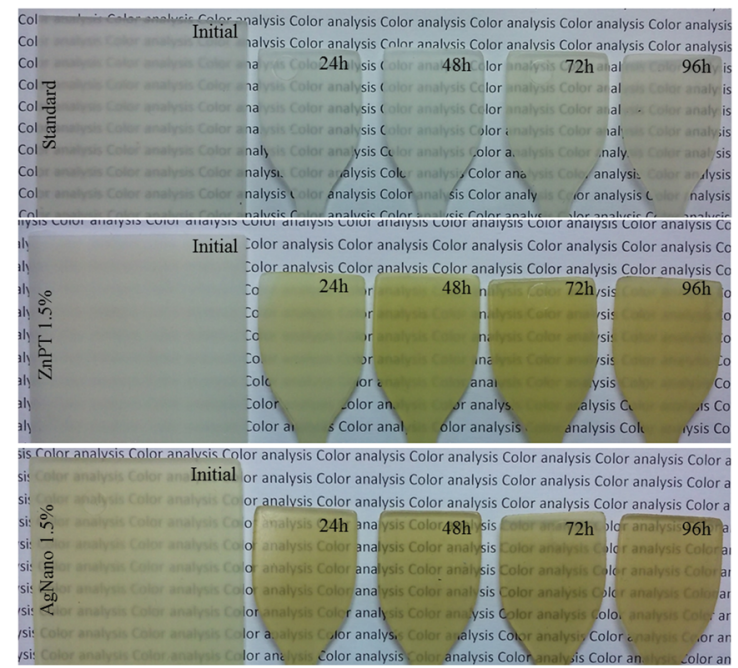

Figure 2. Color variation comparing Standard TPE samples and TPE incorporated with $1.5 \%$ of $\mathrm{ZnPT}$ and $1.5 \%$ AgNano, before and after 96 hours of UV light exposure.
Yellowness of the sample incorporated with AgNano was accentuated after 96 hours of UV light, the yellowness value (b*) changed from 11.1 to 20.1. The decrease in transparency and increase in yellowness $\left(b^{*}\right)$ has been already reported by $\mathrm{Choi}^{16}$, and Martinez-Abad ${ }^{27}$ and is associated to silver oxidation, as shown in equation (4).

$$
\begin{aligned}
& \mathrm{O}_{2(\text { aq. })}+4 \mathrm{H}_{3} \mathrm{O}^{+}+4 \mathrm{Ag}_{(s)} \rightarrow \\
& 4 \mathrm{Ag}_{(\text {aq. })}^{+}+6 \mathrm{H}_{2} \mathrm{O}
\end{aligned}
$$

In SEBS compounds, color variation is normal and could be ascribed to degradation of styrene and conjugated bond sequences in the polymer backbone, hence becoming similar to stilbene (which is yellow) ${ }^{28,29}$. In the Standard sample, the global color $(\Delta \mathrm{E})$ change after $96 \mathrm{~h}$ under UV light was of 2.4 , results up to 2.0 are visually imperceptible.

At infrared assay, there were no difference between the spectra from Standard and AgNano (Figure 3a and Figure 


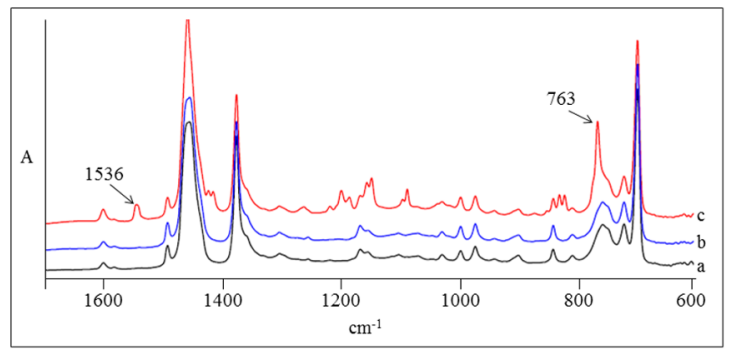

Figure 3. FTIR-ATR in the region from $1700-1$ to $600 \mathrm{~cm}^{-1}$ of samples (a) Standard, (b) $1.5 \%$ AgNano and (c) $1.5 \% \mathrm{ZnPT}$.

3b). Differences were only noticed in the ZnPT spectra, this fact may be due to the easy leaching of zinc pyrithione to the surface becoming detectable. In Figure 3c, an increment can be observed in the band intensity between $1300 \mathrm{~cm}^{-1}$ and 800 $\mathrm{cm}^{-1}$, which could be assigned to an increase in isotactic PP amount from the masterbach ${ }^{30}$. An increase in band intensity at $763 \mathrm{~cm}^{-1}$ was attributed to aromatic $=\mathrm{C}-\mathrm{H}$ out-of-plane deformation vibrations from the pirithione structure. The weak band at $1536 \mathrm{~cm}^{-1}$ depicts that the coordination of oxygen atoms to $\mathrm{Zn}$ is in chelated form, if they were in ionic form, a peak at $1576 \mathrm{~cm}^{-1}$ would be observed ${ }^{31}$.

The reduction in E. coli population did not differ significantly between $\mathrm{ZnPT}$ and $\mathrm{AgNano}$ incorporated TPE samples $(E$. coli $-\mathrm{t}=2.60 ; \mathrm{df}=2.01 ; \mathrm{p}=0.12)$. The $S$. aureus counts were significantly different between $\mathrm{ZnPT}$ and AgNano incorporated compounds $(S$. aureus $-\mathrm{t}=4.43 ; \mathrm{df}=2.01 ; \mathrm{p}=$ 0.05 ), with better effectiveness of $\mathrm{ZnPT}$ (Figure 4).

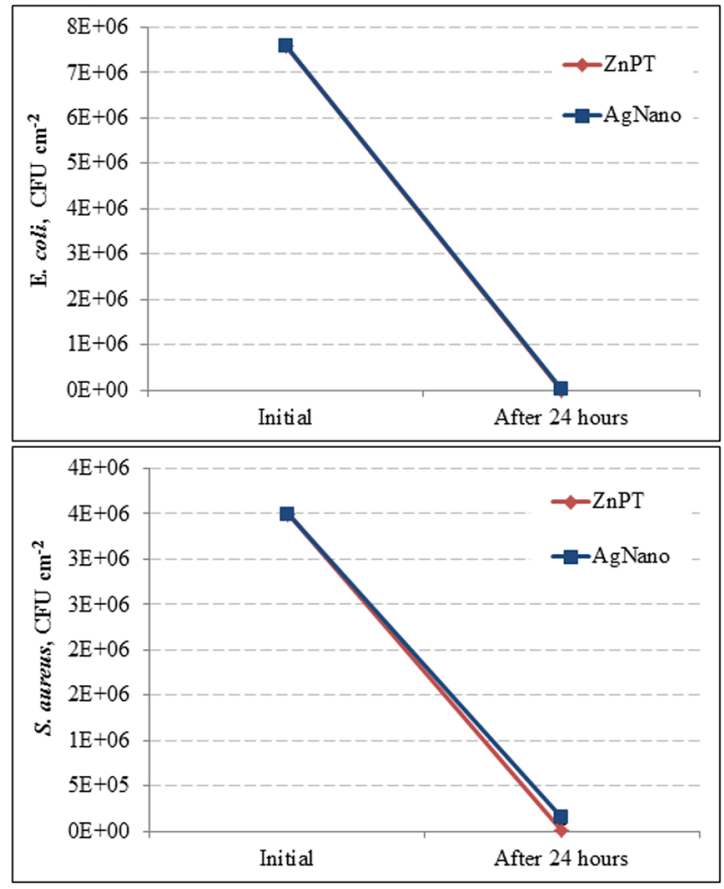

Figure 4. Variation in the number of colony forming units (CFU) of: (a) Escherichia coli and (b) Staphylococcus aureus population between the initial and final time in ZnPT and AgNano TPE incorporated samples.
A good inhibitory effect towards Gram-negative and Gram-positive bacteria was obtained in both additives tested, even after undergoing typical polymer industrial processing. Moreover, a better bactericide effect of $\mathrm{ZnPT}$ compared to AgNano was observed. Dagostin and coworkers ${ }^{6}$ also found a better antimicrobial result of $\mathrm{ZnPT}$ incorporated into polyurethane foam matrices than Triclosan ${ }^{\circledR}$ and isothiazolone. Previous studies report that pyrithione can penetrate bacterial cytosol besides acting in cell membrane ${ }^{32}$. Once inside the cell, the chelating mechanism of ZnPT promotes a disorder in the cell envelope, owing to the leakage of intracellular components as well as the inhibition of nutrient uptake?

In the present investigation, metal uptake by bacteria was not explored. However, Gram-negative bacteria were most susceptible to the action of both additives while $S$. aureus was more susceptible to $\mathrm{ZnPT}$. The differential effectiveness observed between the additives tested herein may be related to the way in which these metals operate. Nanosilver is positively charged and bacterial cell wall is negative, which leads to an electrical disturbance; pyrithione is a chelating agent that can sequestrate metal ions which are important in bacterial cell conformation ${ }^{7}$. This property also causes an electrical disorder in bacteria membranes, mainly Gram-negative ones, due to the action on lipopolysaccharide groups, present in the outer membrane of these microorganisms ${ }^{33}$. It was shown that zinc pyrithione leads to decrease in intracellular adenosine triphosphate amount in Gram-negative bacteria species Escherichia coli and Pseudomonas aeruginosa ${ }^{7}$. Also, the treatment with $\mathrm{ZnPT}$ induces the production of reactive oxygen species $(\mathrm{ROS})^{34,35}$, which are related to the antibacterial action ${ }^{36}$. Thus, the ROS from zinc ions, such as hydrogen peroxide, would be associated to the toxic effects of $\mathrm{ZnPT}^{37}$.

According to Standard JIS Z 280124, in order to accept the material as being antibacterial, the effectiveness value must be equal to or higher than 2. In the present study, the antimicrobial incorporated compounds did not reach the $\mathrm{R}$ value of 2.0 in the measurement against the $S$. aureus population. However, against the $E$. coli population, the $\mathrm{ZnPT}$ compounds presented better antibacterial effectiveness $(\mathrm{R}=$ 3.1) than AgNano $(\mathrm{R}=2.0)$ compounds Table 3.

Results of antifungal activity are presented in Figure 5. The $\mathrm{ZnPT}$ antifungal activity against $A$. niger (Figure 5a), C. albicans (Figure 5b) and C. cladosporioides (Figure 5c) are indicated by the appearance of inhibition zones of $7 \mathrm{~mm}$, $2 \mathrm{~mm}$ and $6 \mathrm{~mm}$, respectively. There was no inhibition zone in samples containing AgNano; however, these samples did not present fungal growth on their surfaces (Figure 5).

Inhibition zone in sample with $\mathrm{ZnPT}$ and other organic antifungal agents have been ascribed to the fact that this component leaches from the polymer to the ambient ${ }^{5,38,39}$. According to Coulthwaite et al. ${ }^{5}$ a zone of inhibition means that free molecules of the biocide are on the surface of the polymer and are released in sufficient quantities into the surrounding culture medium where the sensitive organisms 
Table 3. Percentage of bacterial population reduction after $24 \mathrm{~h}$ of incubation and $(\mathrm{R})$ antibacterial effectiveness values.

\begin{tabular}{lcccc}
\hline & \multicolumn{2}{c}{ E. coli } & \multicolumn{2}{c}{ S. aureus } \\
Samples & Reduction, \% & R & Reduction, \% & R \\
\hline ZnPT & 99.97 & 3.1 & 99.65 & 1.7 \\
AgNano & 99.65 & 2.0 & 95.54 & 0.6 \\
\hline
\end{tabular}

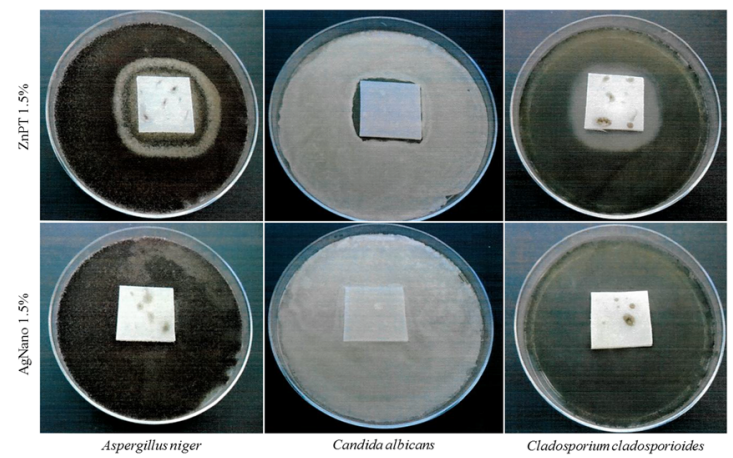

Figure 5. Antifungal activity of $\mathrm{ZnPT}$ and AgNano incorporated samples: (a) Aspergillus niger, (b) Candida albicans, (c) Cladosporium cladosporioides.

are present. The characteristics of the polymeric matrix related to its water diffusion ability ${ }^{40,41}$, and the structure of the polymer system ${ }^{42}$ can influence biocidal action, since it may facilitate the release of the antifungal agent. For example, Silaparson et al. ${ }^{43}$ show that it is more difficult for Triclosan ${ }^{\circledR}$ to be diffused through amorphous and rigid thermoplastics (such as polystyrene and polyvinyl chloride) than through soft and crystalline thermoplastics (such as polypropylene and polyethylene).

The antifungal capability of $\mathrm{ZnPT}$ is widely known ${ }^{44}$. Chandler and Sege ${ }^{13}$ have demonstrated that inhibition of fungi growth by pyrithione is the result of the reduction in membrane transport systems. In addition, the source of $\mathrm{ZnPT}$ antifungal efficacy is related to the balance between the acquisition, storage and usage of metals by the fungus ${ }^{45}$. In that case, the metal starvation ${ }^{34}$ or high intracellular availability ${ }^{8,45}$ will affect the activity of iron-sulfur proteins involved in diverse metabolic functions required for microbial growth $^{46}$. Ion exchange is a slow process and this can enlarge the biocidal effect of metal-based antimicrobials ${ }^{47}$. Silver nanoparticles have been indicated to prevent the growth of C. albicans through modifications in cell dynamics ${ }^{18,42,48,}$.

On the basis of the results, we infer that better biocide effect of $\mathrm{ZnPT}$ than the $\mathrm{AgNano}$ can be related to the different mechanisms that these substances use to reach the polymer surface. Although few studies report the specific mechanisms of $\mathrm{ZnPT}$ in polymers, it is known that organic additives as ZnPT, n-octylisothiazolin-one (OIT) and Triclosan ${ }^{\circledR}$ are known as migratory and easily leached from polymer matrices, forming an inhibition zone in fungal assays ${ }^{23}$.
Even with no inhibition zone, the sample incorporated with AgNano presented no mycelia growth on its surface. For silver nanoparticles is reported that to achieve biocide properties in polymer, silver ions must migrate to the polymer surface to get in contact with fungi and bacteria cells, for this, water must permeate the polymer chain to oxidize the silver nanoparticles (as shown in equation 4) ${ }^{16,40,49,50}$.

\section{Conclusions}

Overall data obtained in our study showed a good antimicrobial activity of ZnPT-incorporated TPE materials against all the fungus and bacterial species tested. However, the precise mechanisms require further investigation. Samples prepared with AgNano also presented bactericidal action, however with no fungistatic effect. No relevant modification in mechanical properties was observed, showing that there was a small interaction between the additive and polymer. Owing to the color modification in TPE materials containing both additives, the industrial utilization of these incorporated materials will be restricted to applications in which pigmentation would not represent a market problem.

\section{Acknowledgements}

The authors would like to thank FINEP for the financial support (03.13.0280.00) and Softer Brasil Compostos Termoplásticos LTDA for infrastructure support. A special thanks to the additive supplier Ipel Itibanyl Produtos Especiais Ltda.

\section{References}

1. Leung WK, Lau APS, Yeung KL. Bactericidal and sporicidal performance of a polymer-encapsulated chlorine dioxide-coated surface. Journal of Applied Microbiology. 2009;106(5):1463-1472.

2. Prüss A, Giroult E, Rushbrook P, eds. Safe management of wastes from health-care activities. Geneva: World Health Organization; 1999.

3. Carpentier B, Cerf O. Biofilms and their consequences, with particular reference to hygiene in the food industry. Journal of Applied Bacteriology. 1993;75(6):499-511.

4. Page K, Wilson M, Parkin IP. Antimicrobial surfaces and their potential in reducing the role of the inanimate environment in the incidence of hospital-acquired infections. Journal of Materials Chemistry. 2009;19(23):3819-3831.

5. Coulthwaite L, Bayley K, Liauw C, Craig G, Verran J. The effect of free and encapsulated OIT on the biodeterioration of plasticised PVC during burial in soil for 20 months. International Biodeterioration \& Biodegradation. 2005;56(2):86-93.

6. Dagostin VS, Golçalves DL, Pacheco CB, Almeida WB, Thomé IP, Pich CT, et al. Bactericidal polyurethane foam mattresses: Microbiological characterization and effectiveness. Materials Science and Engineering: C. 2010;30(5):705-708. 
7. Dinning AJ, Al-Adham ISI, Eastwood IM, Austin P, Collier PJ. Pyrithione biocides as inhibitors of bacterial ATP synthesis. Journal of Applied Microbiology. 1998;85(1):141-146.

8. Reeder NL, Kaplan J, Xu J, Youngquist RC, Wallace J, Hu P, et al. Zinc pyrithione inhibits yeast growth through copper influx and inactivation of iron-sulfur proteins. Antimicrobial Agents and Chemotherapy. 2011;55(12):5753-5760.

9. Tozer SA, Kelly S, O’Mahony C, Daly EJ, Nash JF. Aggregate exposure modelling of zinc pyrithione in rinse-off personal cleansing products using a person-orientated approach with market share refinement. Food and Chemical Toxicology. 2015;83:103-110.

10. Bressy C, Hugues C, Margaillan A. Characterization of chemically active antifouling paints using electrochemical impedance spectrometry and erosion tests. Progress in Organic Coatings. 2009;64(1):89-97.

11. Windler L, Height M, Nowack B. Comparative evaluation of antimicrobials for textile applications. Environment International. 2013;53:62-73.

12. Burley JW, Clifford PD. Extending the use of zinc-containing biocides in PVC. Journal of Vinyl \& Additive Technology. 2004;10(2):95-98.

13. Chandler CJ, Segel IH. Mechanism of the antimicrobial action of pyrithione: effects on membrane transport, ATP levels, and protein synthesis. Antimicrobial Agents and Chemotherapy. 1978;14(1):60-68.

14. Guthery E, Seal LA, Anderson EL. Zinc pyrithione in alcoholbased products for skin antisepsis: Persistence of antimicrobial effects. American Journal of Infection Control. 2005;33(1):1522.

15. D'Arcy N. Antimicrobials in plastics: a global review. Plastics Additives and Compounding. 2001;3(12):12-15.

16. Choi O, Deng KK, Kim NJ, Ross L Jr, Surampalli RY, Hu Z. The inhibitory effects of silver nanoparticles, silver ions, and silver chloride colloids on microbial growth. Water Research. 2008;42(12):3066-3074.

17. Dakal TC, Kumar A, Majumdar RS, Yadav V. Mechanistic Basis of Antimicrobial Actions of Silver Nanoparticles. Frontiers in Microbiology. 2016;7:1831.

18. Kim KJ, Sung WS, Suh BK, Moon SK, Choi JS, Kim JG, et al. Antifungal activity and mode of action of silver nano-particles on Candida albicans. Biometals. 2009;22(2):235-242.

19. Morones JR, Elechiguerra JL, Camacho A, Holt K, Kouri JB, Ramírez JT, et al. The bactericidal effect of silver nanoparticles. Nanotechnology. 2005;16(10):2346-2353.

20. Ansari MA, Khan HM, Khan AA, Ahmad MK, Mahdi AA, Pal $\mathrm{R}$, et al. Interaction of silver nanoparticles with Escherichia coli and their cell envelope biomolecules. Journal of Basic Microbiology. 2014;54(9):905-915.

21. Ninganagouda S, Rathod V, Singh D, Hiremath J, Singh AK, Mathew J, et al. Growth Kinetics and Mechanistic Action of Reactive Oxygen Species Released by Silver Nanoparticles from Aspergillus niger on Escherichia coli. BioMed Research International. 2014;2014:753419.
22. Ellison J, Wykoff G, Paul A, Mohseni R, Vasiliev A. Efficient dispersion of coated silver nanoparticles in the polymer matrix. Colloids and Surfaces A: Physicochemical and Engineering Aspects. 2014;447:67-70.

23. Nichols D. Biocide in plastics. Shawbury: Rapra Review Reports 15(12); 2004. $116 \mathrm{p}$.

24. Japanese Industrial Standard (JIS). JIS Z 2801- Antimicrobial products - test for antimicrobial activity and efficacy. Tokio: Japanese Industrial Standard; 2010.

25. Brazilian Association of Technical Standards (ABNT). NBR 15275 - Biological assays - Insole, synthetic laminated and sole-Determination of the resistance to the microbial attack. Rio de Janeiro: ABNT; 2014.

26. Kappock PS, Flaherty P, inventors; Arch Chemicals, Inc., assignee. Discoloration prevention in pyrithione-containing coating compositions. EP1348743 B1. 1997 Feb 21.

27. Martínez-Abad A, Ocio MJ, Lagaron JM. Morphology, physical properties, silver release, and antimicrobial capacity of ionic silver-incorporated poly(1-lactide) films of interest in foodcoating applications. Journal of Applied Polymer Science. 2014;131(21):41001.

28. Allen NS, Edge M, Wilkinson A, Liauw CM, Mourelatou D, Barrio J, et al. Degradation and stabilisation of styreneethylene-butadiene-styrene (SEBS) block copolymer. Polymer Degradation and Stability. 2001;71(1):113-122.

29. Yousif E, Haddad R. Photodegradation and photostabilization of polymers, especially polystyrene: review. SpringerPlus. $2013 ; 2: 398$.

30. Luongo JP. Infrared study of polypropylene. Journal of Applied Polymer Science. 1960;3(9):302-309.

31. Gönen M, Balköse D, Inal F, Ülkü S. Zinc Stearate Production by Precipitation and Fusion Processes. Industrial \& Engineering Chemistry Research. 2005;44(6):1627-1633.

32. Dinning AJ, Al-Adham ISI, Austin P, Collier PJ. A novel assay for the distribution of pyrithione biocides in bacterial cells. Letters in Applied Microbiology. 1998;27(1):1-4.

33. Clifton LA, Skoda MWA, Brun APL, Ciesielski F, Kuzmenko I, Holt SA, et al. Effect of divalent cation removal on the structure of Gram-negative bacterial outer membrane models. Langmuir. 2015;31(1):404-412.

34. Yasokawa D, Murata S, Iwahashi Y, Kitagawa E, Kishi K, Okumura $\mathrm{Y}$, et al. DNA microarray analysis suggests that zinc pyrithione causes iron starvation to the yeast Saccharomyces cerevisiae. Journal of Bioscience and Bioengineering. 2010;109(5):479486.

35. Oyama TM, Saito M, Yonezawa T, Okano Y, Oyama Y. Nanomolar concentrations of zinc pyrithione increase cell susceptibility to oxidative stress induced by hydrogen peroxide in rat thymocytes. Chemosphere. 2012;87(11):1316-1322.

36. Rajavel K, Gomathi R, Manian S, Thangavelu R, Rajendra Kumar RT. In vitro bacterial cytotoxicity of CNTS: reactive oxygen species mediate cell damage edges over direct physical puncturing. Langmuir. 2014;30(2):592-601. 
37. Linley E, Denyer SP, McDonnell G, Simons C, Maillard JY. Use of hydrogen peroxide as a biocide: new consideration of its mechanisms of biocidal action. Journal of Antimicrobial Chemotherapy. 2012;67(7):1589-1596.

38. Sørensen G, Nielsen AL, Pedersen MM, Poulsen S, Nissen $\mathrm{H}$, Poulsen $\mathrm{M}$, et al. Controlled release of biocide from silica microparticles in wood paint. Progress in Organic Coatings. 2010;68(4):299-306.

39. Jämsä S, Mahlberg R, Holopainen U, Ropponen J, Savolainen A, Ritschkoff AC. Slow release of a biocidal agent from polymeric microcapsules for preventing biodeterioration. Progress in Organic Coatings. 2013;76(1):269-276.

40. Kumar R, Münstedt H. Silver ion release from antimicrobial polyamide/silver composites. Biomaterials. 2005;26(14):2081-2088.

41. Damm C, Münstedt H, Rösch A. Long-term antimicrobial polyamide 6/silver-nanocomposites. Journal of Materials Science. 2007;42(15):6067-6073.

42. Wady AF, Machado AL, Zucolotto V, Zamperini CA, Berni E, Vergani CE. Evaluation of Candida albicans adhesion and biofilm formation on a denture base acrylic resin containing silver nanoparticles. Journal of Applied Microbiology. 2012;112(6):1163-1172.

43. Silapasorn K, Sombatsompop K, Kositchaiyong A, Wimolmala E, Markpin T, Sombatsompop N. Effect of chemical structure of thermoplastics on antibacterial activity and physical diffusion of triclosan doped in vinyl thermoplastics and their composites with $\mathrm{CaCO}_{3}$. Journal of Applied Polymer Science. 2011;121(1):253-261.
44. Reeder NL, Xu J, Youngquist RS, Schwartz JR, Rust RC, Saunders CW. The antifungal mechanism of action of zinc pyrithione. British Journal of Dermatology. 2011;165(Suppl 2):9-12.

45. Li L, Miao R, Bertram S, Jia X, Ward DM, Kaplan J. A role for iron-sulfur clusters in the regulation of transcription factor YAP5-dependent high iron transcriptional responses in yeast. Journal of Biological Chemistry. 2012;287(42):35709-35721.

46. Li J, Kogan M, Knight SA, Pain D, Dancis A. Yeast mitochondrial protein, Nfs1p, coordinately regulates iron-sulfur cluster proteins, cellular iron uptake, and iron distribution. Journal of Biological Chemistry. 1999;274(46):33025-33034.

47. Kwakye-Awuah B, Williams C, Kenward MA, Radecka I. Antimicrobial action and efficiency of silver-loaded zeolite X. Journal of Applied Microbiology. 2007;104(5):1516-1524.

48. Panáček A, Kolář M, Večeřová R, Prucek R, Soukupová J, Kryštof V, et al. Antifungal activity of silver nanoparticles against Candida spp. Biomaterials. 2009;30(31):63336340 .

49. Radheshkumar C, Münstedt $H$. Antimicrobial polymers from polypropylene/silver composites - $\mathrm{Ag}^{+}$release measured by anode stripping voltammetry. Reactive and Functional Polymers. 2006;66(7):780-788

50. Triebel C, Vasylyev S, Damm C, Stara H, Özpinar C, Hausmann $\mathrm{S}$, et al. Polyurethane/silver-nanocomposites with enhanced silver ion release using multifunctional invertible polyesters. Journal of Materials Chemistry. 2011;21(12):4377-4383. 